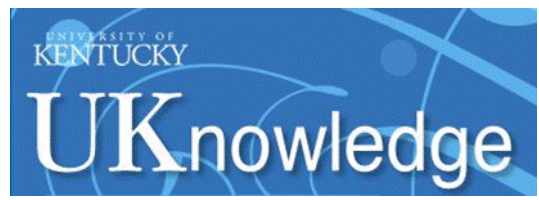

University of Kentucky

UKnowledge

\title{
Exploring the Efficiency and Cost Limits of Fractional hp Axial Flux PM Machine Designs
}

\author{
Narges Taran \\ University of Kentucky, narges.taran@uky.edu \\ Vandana Rallabandi \\ University of Kentucky, vandana.rallabandi@uky.edu \\ Greg Heins \\ Regal Beloit Corporation, Australia \\ Dan M. Ionel \\ University of Kentucky, dan.ionel@uky.edu
}

Follow this and additional works at: https://uknowledge.uky.edu/peik_facpub

Part of the Power and Energy Commons

Right click to open a feedback form in a new tab to let us know how this document benefits you.

\section{Repository Citation}

Taran, Narges; Rallabandi, Vandana; Heins, Greg; and Ionel, Dan M., "Exploring the Efficiency and Cost Limits of Fractional hp Axial Flux PM Machine Designs" (2018). Power and Energy Institute of Kentucky Faculty Publications. 32.

https://uknowledge.uky.edu/peik_facpub/32

This Conference Proceeding is brought to you for free and open access by the Power and Energy Institute of Kentucky at UKnowledge. It has been accepted for inclusion in Power and Energy Institute of Kentucky Faculty Publications by an authorized administrator of UKnowledge. For more information, please contact UKnowledge@lsv.uky.edu. 


\title{
Exploring the Efficiency and Cost Limits of Fractional hp Axial Flux PM Machine Designs
}

\author{
Digital Object Identifier (DOI) \\ https://doi.org/10.1109/ECCE.2018.8557562
}

Notes/Citation Information

Published in 2018 IEEE Energy Conversion Congress and Exposition (ECCE).

(C) 2018 IEEE Copyright Notice. "Personal use of this material is permitted. Permission from IEEE must be obtained for all other uses, in any current or futuremedia, including reprinting/republishing this material for advertising or promotional purposes, creating new collective works, for resale or redistribution to servers or lists, or reuseof any copyrighted component of this work in other works."

The document available for download is the authors' manuscript version that is accepted for publication. The final published version is copyrighted by IEEE and will be available as: N. Taran, V. Rallabandi, G. Heins and D. M.lonel, "Exploring the Efficiency and Cost Limits of Fractional hp Axial Flux PM Machine Designs," Rec. 2018 IEEE Energy Conversion Congress and Exposition (ECCE), Portland,OR, Sept 2018, 6p. 


\section{Exploring the Efficiency and Cost Limits of Fractional hp Axial Flux PM Machine Designs}

\author{
Narges Taran \\ SPARK Lab, ECE Dept. \\ University of Kentucky \\ Lexington, KY, USA \\ narges.taran@uky.edu
}

\author{
Vandana Rallabandi \\ SPARK Lab, ECE Dept. \\ University of Kentucky \\ Lexington, KY, USA \\ vandana.rallabandi@uky.edu
}

\author{
Greg Heins \\ Regal Beloit Corp. \\ Research and Development \\ Rowville, VIC, Australia \\ greg.heins@ regalbeloit.com
}

\author{
Dan M. Ionel \\ SPARK Lab, ECE Dept. \\ University of Kentucky \\ Lexington, KY, USA \\ dan.ionel@uky.edu
}

\begin{abstract}
Optimizing the design of electric machines is a vital step in ensuring the economical use of active materials. The three-dimensional flux paths in axial flux PM (AFPM) machines necessitate the use of computationally expensive 3D electromagnetic analysis. Furthermore, a large number of design evaluations is required to find the optimum, causing the total computation time to be excessively long. In view of this, a two-level surrogate assisted algorithm capable of handling such expensive optimization problems is introduced, which substantially reduces the number of FEA evaluations. The proposed algorithm is employed to optimally design an AFPM machine within a specified envelope, identifying the limits of cost and efficiency. Optimized designs with different rotor polarities are systematically compared in order to form the basis for a set of generalized design rules.
\end{abstract}

Index Terms-Axial flux permanent magnet, surrogate assisted, multi-objective, optimization, number of poles, SPM.

\section{INTRODUCTION}

The design and optimization of axial flux permanent magnet (AFPM) machines are of great interest due to many of their advantages such as higher torque density and efficiency. Their disc shape makes it practical to achieve designs with a larger diameter and a higher number of poles. The possibility to have a higher pole count leads to potential performance improvements. Determining the number of rotor poles and subsequently stator slots greatly impacts the outcomes of the electric machine design optimization [1]. This paper is a systematic investigation of those impacts for a surface mounted AFPM machine.

Recently, the fractional slot concentrated winding (FSCW) has attracted attention for its application in surface mounted PM machines [2]-[4]. Its main advantages include shorter end coils, a simple structure, and improved fault tolerance. The use of double layer FSCW can mitigate the core and PM losses as opposed to its single layer counterpart. Also, in case of axial flux configurations, the double layer winding can yield an increased active diameter within a constrained total diameter, due to the reduction in coil thickness.

Studies on surface mounted PM machines (SPM) with a concentrated winding provide the principles for selecting the best combinations for the number of slots and poles. They propose a slot per pole per phase less than or equal to 0.5 [5], $N_{s}=N_{p} \pm 1$ or $N_{s}=N_{p} \pm 2$ [6]-[9], and $N_{s}>N_{p}$
[10], where $N_{s}$ and $N_{r}$ are the number of slots and poles, respectively. Based on the above guidelines, four slot/pole combinations $(12 / 10,24 / 20,36 / 30,48 / 40)$ with a double layer concentrated winding are selected.

The main shortcomings of the studies conducted on the effect of slot/pole combinations is that they rely on simplistic assumptions, such as a constant yoke thickness, and the use of analytical approches and/or 2D models for machines with 3D flux paths [3], [11]-[14], which results in comparing topologies that are not truly optimal designs for their pole count. On the other hand, this paper systematically investigates the optimal design and pole count selection of a surface mounted AFPM machine. The design comparison is performed over very wide search spaces, and optimum designs are identified for AFPM machine topologies, employing 10, 20, 30 and 40 poles. All the candidate machines are designed for the same power and with identical total axial lengths and diameters.

Considering that cost competetiveness and design efficiency are the most important criteria from the perspective of manufacturers and customers, the optimization objectives are considered to be the total loss and cost [15]. The optimization is based on differential evolution and employs a two-level surrogate assisted algorithm that is capable of employing 3D models as it considerably reduces the number of FEA design evaluations required [16]. Each topology with a different pole count has reached to the Pareto front with about 200 3D FEA evaluations, in addition to thousands of surrogate model interpolations. Best compromise designs which achieve a good trade off between loss and mass are identified.

It is reasonable to expect the best compromise design to vary for different pole counts. One of the goals of this study is to investigate those varying factors in order to achieve generalized rules for a suitable initial design of SPM machines with different polarities. The results of this study can be used as a basis for formulating generalized design rules for AFPM machines.

Generally, as the number of poles and slots increases, the copper loss decreases, due to the reduced end winding length. On the other hand, the increase in the fundamental frequency causes more core losses. Therefore, a pole count, which achieves a proper trade-off between copper and core losses, for a given application and dimensional constraints, 


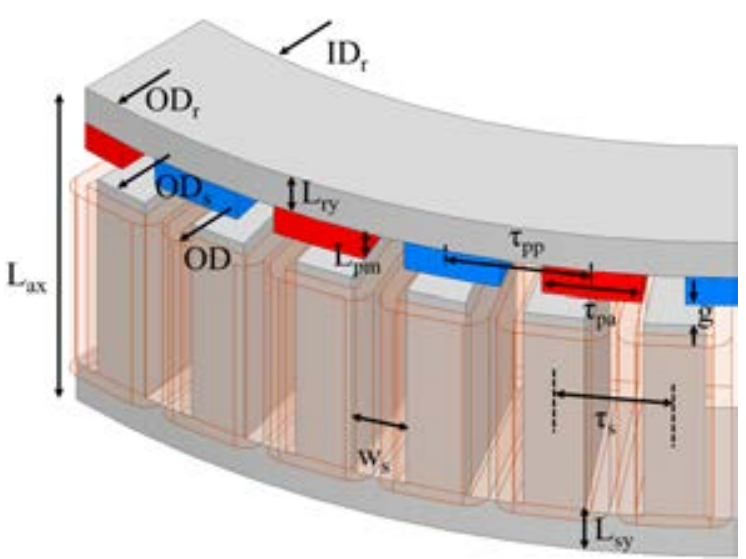

Fig. 1. The geometrical independent variables included in the process of design optimization. The variables are introduced to the algorithm as ratios.

TABLE I

INDEPENDENT OPTIMIZATION VARIABLES AND CORRESPONDING LIMITS, EXEMPLIFIED FOR THE CONFIGURATION WITH 40 POLES.

\begin{tabular}{llrc}
\hline Variable & Description & Min & Max \\
\hline$g$ & Air-gap $[\mathrm{mm}]$ & 1.50 & 4.00 \\
$k_{r y}$ & $L_{r y} / L_{a x}$ & 0.07 & 0.25 \\
$k_{s y}$ & $L_{s y} / L_{a x}$ & 0.07 & 0.25 \\
$k_{p m}$ & $L_{p m} / L_{a x}$ & 0.06 & 0.25 \\
$k_{d s}$ & $I D_{s} / O D_{s}$ & 0.48 & 0.80 \\
$k_{o h}$ & $\left(O D_{r}-O D_{s}\right) /\left(O D-O D_{s}\right)$ & -1.00 & 1.00 \\
$k_{s w}$ & $w_{s} / \tau_{s, i d}$ & 0.45 & 0.90 \\
$k_{p}$ & $\tau_{p a} / \tau_{p p}$ & 0.60 & 0.95 \\
\hline
\end{tabular}

can be identified. The methodology developed in this paper can be utilized to identify the number of poles most suitable for a specified application.

The paper is structured as follows: the next section introduces the AFPM machine specifications and its 3D parametric model. The selected objectives and geometrical variables are explained. Section III implements the optimization algorithm which enables the use of expensive 3D models. The results are discussed and validated in sections IV and V, respectively. The study concludes in section VI.

\section{Specifications of the AFPM Machines AND 3D PARAMETRIC MODELS}

The AFPM machines to be optimized are single stator single rotor configurations with surface mounted Neodymium magnets and concentrated non-overlapping windings. The slot/pole combinations are 12/10, 24/20, 36/30, and 48/40. The frame size is kept the same in all topologies. The machines are designed to produce the rated torque of $5.4 \mathrm{Nm}$ at $1050 \mathrm{rpm}$.

Two optimization objective functions are defined for the total loss, $F_{l}$, and active material cost, $F_{c}$ :

$$
\begin{aligned}
& F_{l}=W_{C u}+W_{c}+W_{p m}, \\
& F_{c}=m_{c}+3 \cdot m_{C u}+24 \cdot m_{p m},
\end{aligned}
$$

where $W_{C u}, W_{c}$, and $W_{p m}$ stand for the copper, stator core, and PM eddy losses. The preliminary studies showed that the rotor core loss is a negligible portion of the total loss in this

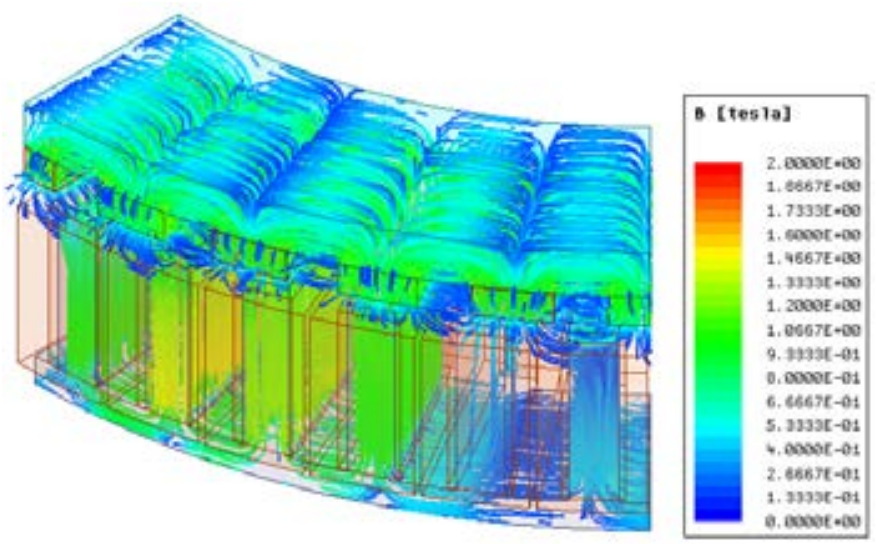

Fig. 2. The 3D flux lines distribution of an exemplified design with 40 poles.

study, and is therefore not considered in the analysis. The total mass of the stator and rotor core are represented with $m_{c}$, and the copper and magnet mass are shown with $m_{C u}$ and $m_{p m}$, respectively. The mass is calculated in $\mathrm{kg}$ and the steel cost per $\mathrm{kg}$ is considered as the one-unit reference [17].

The search space for the optimal design is assigned to be very wide, i.e., the ranges of the optimization variables are as wide as possible, with only geometrical limitations taken into account, to include the absolute limits of the minimum cost and loss achievable. Therefore, the variables are limited either to prevent the intersection of various geometrical components or to address mechanical constraints such as the minimum airgap or yoke thickness.

Eight geometrical variables are selected as optimization variables, as illustrated in Fig. 1 and Table I. The flux lines distribution for the 40 pole topology, as an instance, is presented in Fig. 2. The variables are defined as ratios to ensure their independence. Only the air-gap is defined as an absolute value, in $\mathrm{mm}$. The variables in the axial direction are divided by the total axial length, $L_{a x}$. The slot depth is calculated for a constant overall axial length.

The over-hang ratio, $k_{o h}$, is defined as values between -1 and +1 . The positive values indicate over-hang (that is, the magnet radial length is greater than the stator radial length with the same average radius), while negative values represent under-hang (that is, the magnet radial length is less than the stator radial length with the same average radius). Taking overhang into account, particularly in cost sensitive designs, is helpful in PM volume reduction. The rated torque produced by each design is achieved through a two-pass analysis where the current is adjusted in the final stage.

\section{Two-LEVEl Surrogate Assisted Optimization}

The flux for an AFPM machine is in both axial and circumferential directions. The flux leakage occurs in 3D, as can be observed in Fig. 2. Also, the tooth width variation in the radial direction makes the stator core in the inner diameter prone to saturation. Two-dimensional or quasi-3D models cannot capture the effects of end coils and overhang. These are 


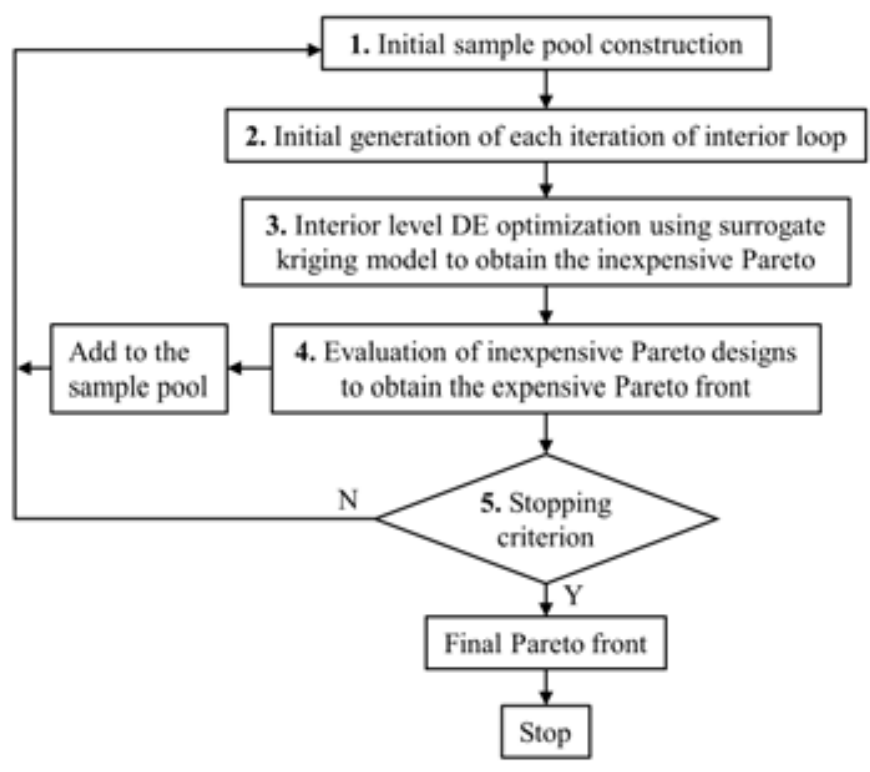

(a)

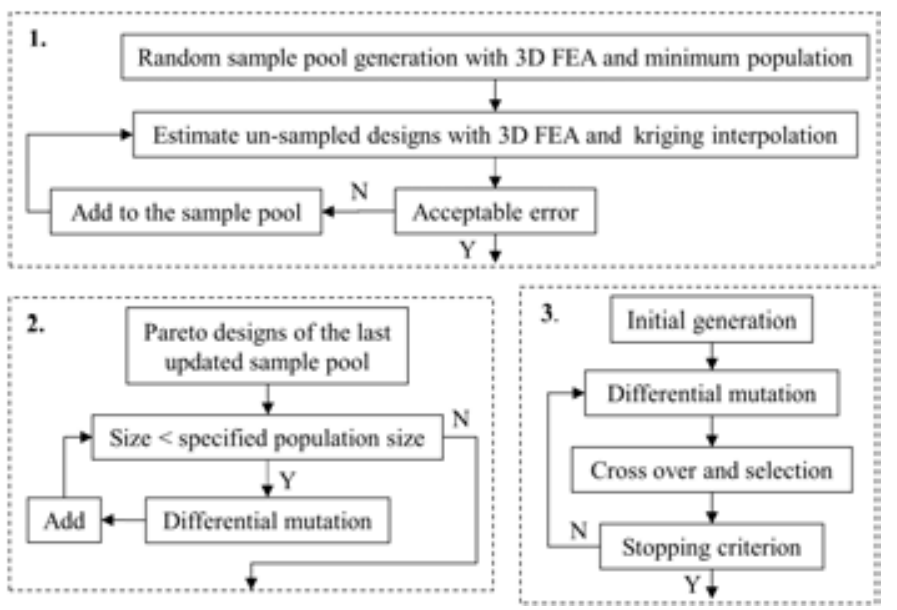

(b)

Fig. 3. (a) The flowchart of the two-level surrogate assisted algorithm, proposed for multi-objective optimization of electric machines with 3D FEA models. (b) The details of blocks 1, 2, and 3.

some of the reasons necessitating the use of computationally expensive 3D models for AFPM machines.

Generally, thousands of design evaluations are required to identify the Pareto front [15]. Moreover, the full exploration of a wide design space, as is undertaken in this paper, would typically require even more designs to be evaluated. For these reasons, the use of 3D FEA models with conventional algorithms is simply unaffordable. Surrogate assisted optimization algorithms make it feasible to evaluate a larger number of designs. In this paper, a new two-level surrogate assisted differential evolution multi-objective optimization (SAMODE) is employed in order to identify the Pareto front accurately with a minimum number of expensive design evaluations.

The flowchart representing the new optimization algorithm is illustrated in Fig. 3. This is a two-level surrogate-assisted

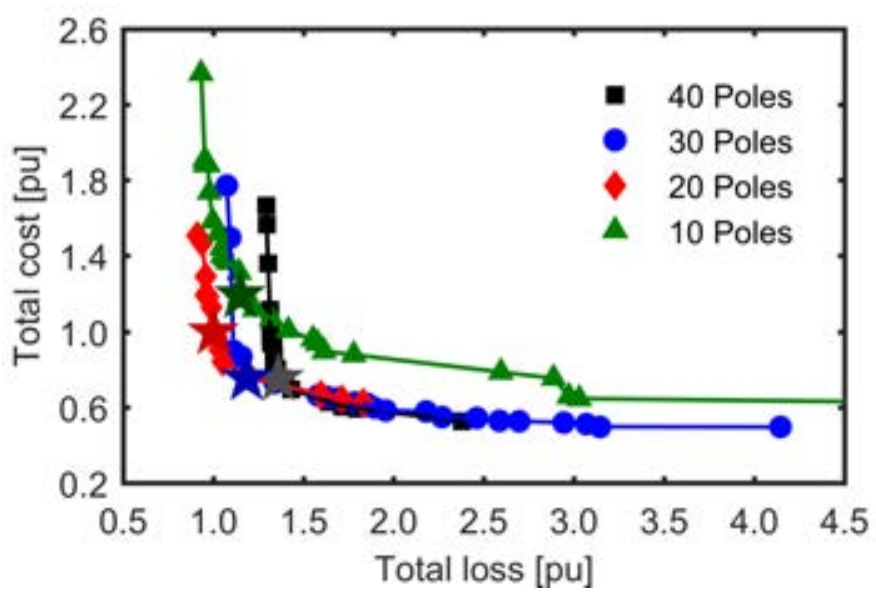

Fig. 4. Pareto fronts obtained for the machines with different pole count, employing 3D FEA models. A representative design of each topology is marked with $\star$. The per-unit system is based on the representative design with the highest efficiency (20 pole topology marked with $\star$ ).

TABLE II

THE PER-UNIT VALUE OF REPRESENTATIVE OPTIMUM DESIGNS FOR DIFFERENT POLE COUNTS. THE 20 POLE DESIGN REPRESENTS THE BASE.

\begin{tabular}{|c|c|c|c|c|c|}
\hline \multicolumn{2}{|c|}{ Number of poles } & 40 & 30 & 20 & 10 \\
\hline \multirow{4}{*}{$\begin{array}{l}\sum^{\infty} \\
\sum^{\tilde{J}}\end{array}$} & Copper & 0.77 & 0.94 & 1.00 & 1.14 \\
\hline & Steel & 0.78 & 0.80 & 1.00 & 1.26 \\
\hline & PM & 1.31 & 0.62 & 1.00 & 1.31 \\
\hline & Total & 0.76 & 0.81 & 1.00 & 1.21 \\
\hline \multirow{4}{*}{$\overrightarrow{0}$} & Copper & 0.68 & 0.84 & 1.00 & 1.01 \\
\hline & Steel & 0.78 & 0.80 & 1.00 & 1.26 \\
\hline & PM & 0.77 & 0.65 & 1.00 & 1.31 \\
\hline & Total & 0.75 & 0.76 & 1.00 & 1.19 \\
\hline \multirow{4}{*}{$\begin{array}{l}\infty \\
0 \\
0 \\
0\end{array}$} & Copper & 1.43 & 1.49 & 1.00 & 1.63 \\
\hline & Core & 1.71 & 1.17 & 1.00 & 0.61 \\
\hline & PM & 0.20 & 0.49 & 1.00 & 1.20 \\
\hline & Total & 1.38 & 1.18 & 1.00 & 1.15 \\
\hline \multicolumn{2}{|c|}{ Emag. efficiency [\%] } & 92.7 & 93.7 & 94.6 & 93.8 \\
\hline
\end{tabular}

algorithm taking advantage of differential evolution and kriging models. The flowchart is composed of an exterior and an interior level loop. The exterior loop is an evolutionary algorithm, replacing the regeneration step with an interior loop. The interior loop is based on a multi-objective differential evolution (MODE) algorithm that employs kriging models for function evaluations [16].

The Gaussian process prediction [18], known as kriging in geostatics, is a local fitting model that, unlike conventional curve fitting methods, does not fit a global polynomial function. The kriging model puts more weight on sampled data points in the vicinity of the unsampled data, providing nonlinear estimations that are more accurate even for the outliers. Kriging surrogate models can be divided into trend and residual components, based on [19] 


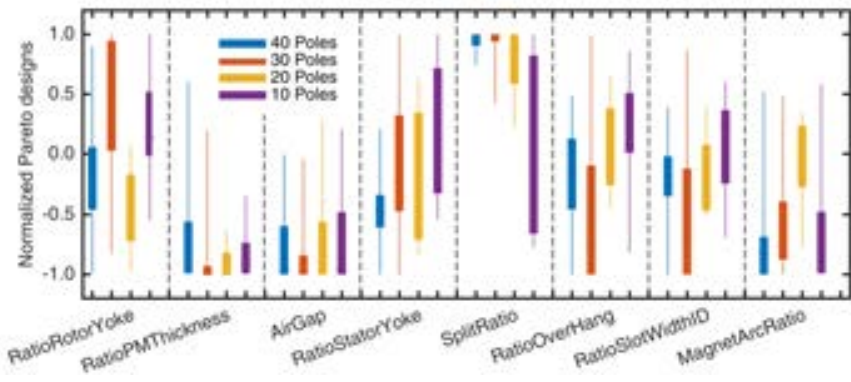

Fig. 5. Distribution of the design variables for the Pareto designs obtained for the topologies with different pole counts.

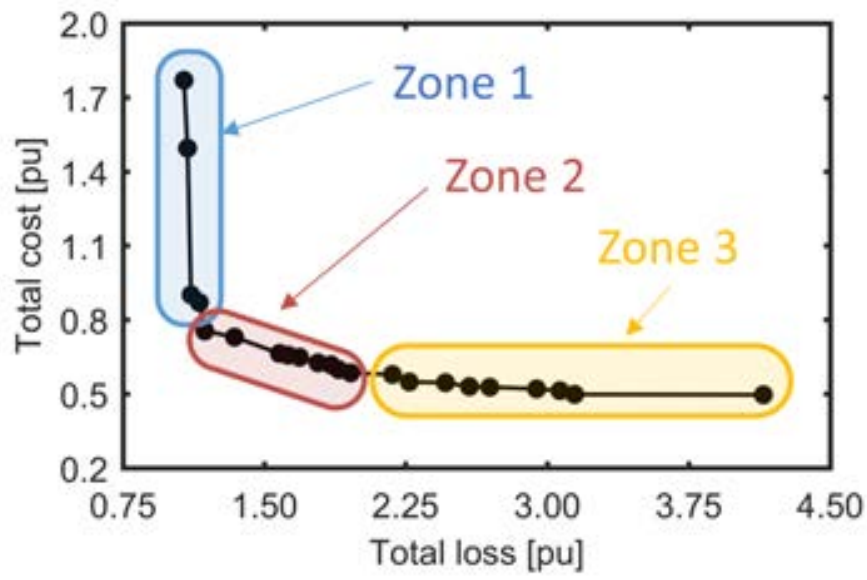

Fig. 6. Pareto front obtained for the machine with 30 poles, divided into three zones, the vertical (zone 1), the knee in the middle (zone 2), and the horizontal section (zone 3).

$$
\begin{aligned}
& \hat{Y}=\hat{X} \beta+r^{T} R^{-1}(Y-X \beta) ; \\
& r_{i}=\exp \left[-\sum_{t=1}^{k} \theta_{t}\left|\hat{x}_{t}-x_{i, t}\right|^{2}\right], \\
& R_{i, j}=\exp \left[-\sum_{t=1}^{k} \theta_{t}\left|x_{i, t}-x_{j, t}\right|^{2}\right] ; \quad i, j=1, \ldots, n,
\end{aligned}
$$

where $\hat{Y}$ is the response to be predicted based on the known sampled data points, i.e. $X$ and $Y . \beta$ is the matrix of regression coefficients that can be obtained using methods such as least squares. $n$ is the number of samples and $k$ the number of variables. Kriging weights, $r^{T}$ and $R^{-1}$ are derived from the covariance function or semivariogram and maximum likelihood estimation (MLE).

The two level layout provides an approach to evaluate only the most promising designs with expensive 3D FEAs in the exterior loop, while the interior loop provides an approach for evaluating thousands of designs using inexpensive surrogate interpolations. This algorithm, unlike existing surrogate assisted algorithms, does not solely rely on estimated values, and has a dynamic sample pool that increases the initial sample pool size until the estimation error is sufficiently small. Such implementation avoids unnecessary expensive design evaluations while the kriging model resolution gradually improves for designs closer to the Pareto front.

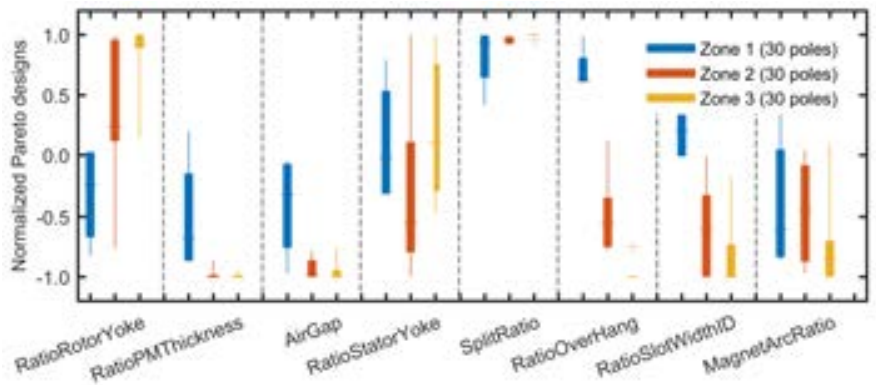

Fig. 7. Distribution of the design variables at different zones of the Pareto front for the topology with 30 poles. This topology is selected due to the its extended asymptotic Pareto front on both sides, illustrated in Fig. 6.

\section{OPTIMIZATION RESUlTS AND DiscUSSION}

The two-level surrogate assisted optimization is performed on the AFPM machines. The Pareto fronts for all pole counts, Fig. 4, represent convex frontiers, so the most significant solutions are located in the knee zone. The designs on the two extremes lead to only negligible improvement of one objective at the cost of substantially deteriorating the other.

For each pole count a representative optimum design is selected from the knee part of the Pareto front, marked with stars in Fig. 4. The breakdown of loss, cost, and active material mass for these designs is shown in Table II and it is observed that for lower numbers of poles and slots, the copper and steel mass increase. The PM mass is affected by several variables including the split ratio, overhang, PM thickness, and PM arc ratio. It shows no specific trend for the designs represented in Table II and comprises a smaller portion of the total mass.

It is also seen in Table II that copper losses reduce initially upon increasing pole count, and then increase. This trend may in part be explained by considering that as the number of poles and slots reduces, the end turn length increases, while the current density reduces. It is observed that the minimum copper loss is obtained for the design with 20 poles, given the specifications and ratings of this study.

The box plot in Fig. 5 illustrates the distribution of variables for designs on the Pareto fronts. This plot can be used to extract general trends as discussed in the following. The PM thickness of the optimal designs located on the Pareto front tends towards their smaller values and more so for lower pole counts. The PM arcs are wider for the lower pole counts. This implies that when the number of poles is lower, designs with thinner PMs and wider PM arcs will be more beneficial. The optimization algorithm reduces the thickness of the PMs with wider arcs that may result in reduction of the PM volume and eddy losses. The stator yoke in optimum designs is generally larger for toplogies with lower pole counts.

The split ratio of the Pareto front designs is generally inclined toward their greater value and more so for higher pole counts. A larger split ratio reduces the active material weight and cost and provides a larger tooth width in the inner diameter, mitigating the risk of saturation. 


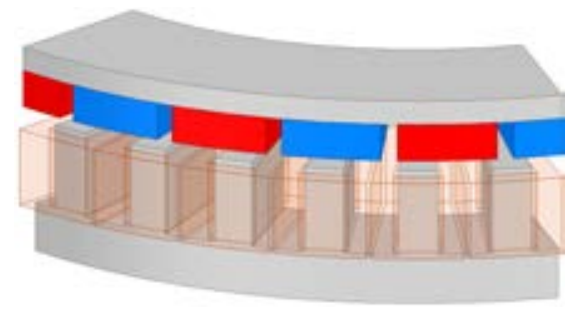

(a)

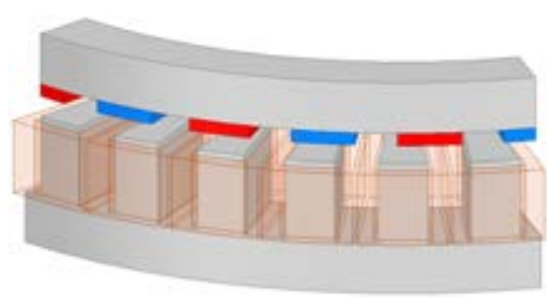

(b)

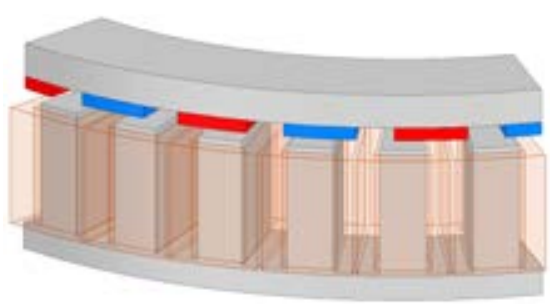

(c)

Fig. 8. The optimum designs obtained for the configuration with 30 poles. (a) The design with minimum loss on the Pareto front, (b) the design with minimum cost on the Pareto front, (c) the design on the knee of the Pareto front with a trade-off between cost and loss.

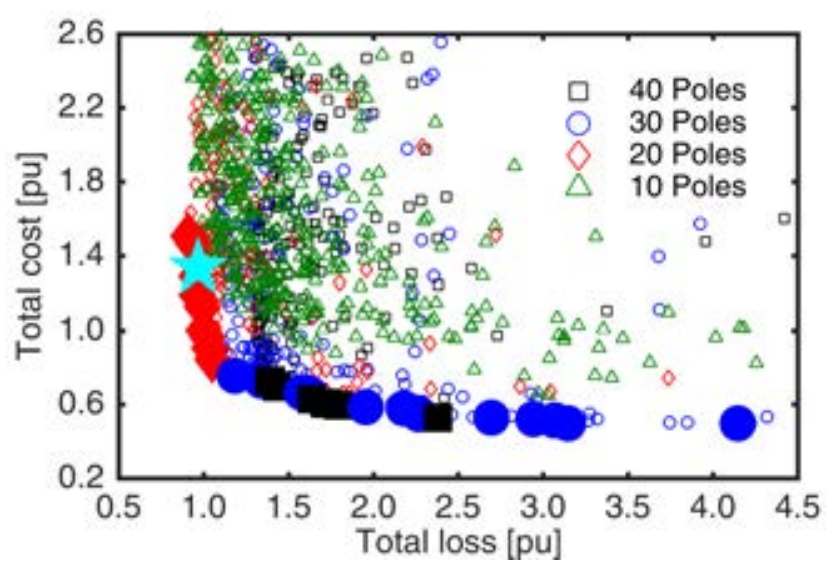

Fig. 9. The overall Pareto front (filled markers) and all of the evaluated designs (hollow markers). The prototyped design is selected to have a high efficiency, marked with $\star$.

To examine the extreme Pareto designs which are located on the tips of the Pareto front, the 30 pole topology is studied because of its extended and asymptotic Pareto front, as shown in Fig. 6. The Pareto front is divided to three clusters, zones 1,2 , and 3 . The designs in zone 1 and 3 are optimized with an emphasis on minimizing the loss and cost, respectively, while the designs in zone 2 display a balance between the two objectives. Based on Fig. 7, the high efficiency designs in zone 1 have a thinner yoke and a larger air-gap. However, the use of more magnet material results in costly designs. More efficient designs also have wider slots, smaller current density and copper loss. The less expensive, albeit less efficient, designs in zone 3 are achieved by reducing the PM thickness, the PM arc, and the overhang ratio, and also by increasing the split ratio.

Extreme cases of designs, with the lowest loss (the topleft corner of Fig. 6) and with the lowest cost (the bottomright corner of Fig. 6) along with a best-compromise design achieving trade-off between loss and cost (marked in Fig. 4 for the 30 pole configuration) are presented in Fig. 8. The design with the least loss in Fig. 8a has thick PMs and a thin yoke such that the cost is mostly associated with the PMs (78\% of the total). Copper and core losses are both equal, at about $17 \mathrm{~W}$. The design in Fig. 8b has the minimum cost and

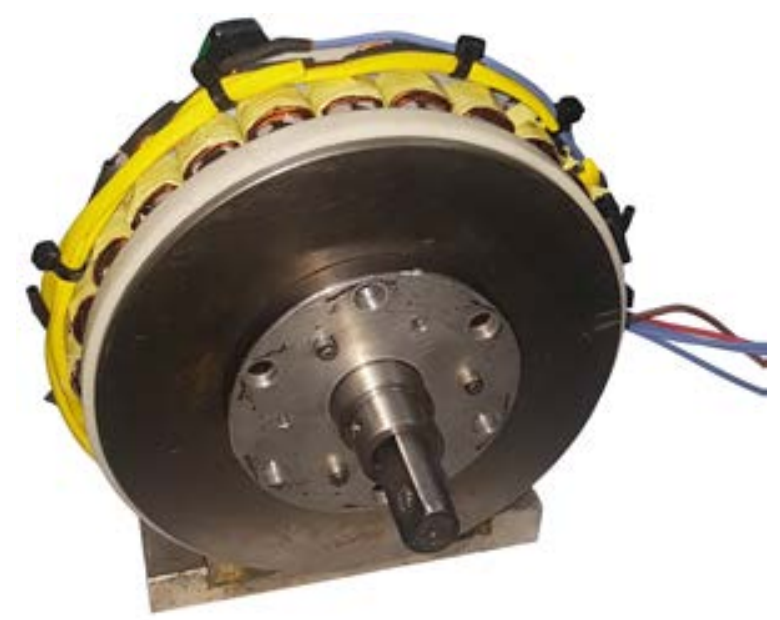

Fig. 10. The ultra high efficiency AFPM machine selected for prototyping based on the comprehensive optimization study with 3D FEA models.

employs very thin PMs and a very thick yoke. The copper loss makes up most of the total loss (134 W out of $140 \mathrm{~W}$ ), while the cost is distributed evenly among the materials. It may be noted that the design from the knee has balanced cost and loss components, a characteristic typically associated with robust optimal designs.

\section{PRototyping AND EXPERIMENTAL VALIDATION}

All the designs evaluated for the four slot/pole combinations along with the Pareto front obtained are represented in Fig. 9. A lower loss design can be obtained from the 20 pole configuration, while a less expensive design can be achieved with 30 or 40 poles. A machine with 20 poles and 24 slots which achieves the ultra high efficiency in excess of $94 \%$ is selected for prototyping, is marked with a star in Fig. 9. The manufactured prototype is presented in Fig. 10.

The estimated performance using the 3D FEA model is verified with measurements and represented in Table III [20]. The spinning loss includes mechanical losses, such as friction and windage, stator core losses, and PM losses. The calculated efficiency uses copper and core losses obtained from the FEA and $6 \mathrm{~W}$ mechanical losses. The results of the measurements and the FEA are in agreement and serve as the basis for the satisfactory validation of the study. 
TABLE III

THE EXPERIMENTAL AND CALCULATED RESULTS OF THE ULTRA HIGH EFFICIENCY AXIAL FLUX SPM MACHINE RATED AT 0.75 HP. THE CALCULATED VALUE OF THE EFFICIENCY USES 3D FEA RESULTS AND A 6 W MECHANICAL LOSS COMPONENT.

\begin{tabular}{llrr}
\hline & & Calculated & Measurement \\
\hline Torque Constant & {$[\mathrm{Nm} / \mathrm{A}]$} & 1.4 & 1.4 \\
Phase resistance & {$[\Omega]$} & 0.39 & 0.37 \\
Conductor loss & {$[\mathrm{W}]$} & 17.4 & 15.3 \\
Core loss & {$[\mathrm{W}]$} & 10.9 & \\
Mechanical loss & {$[\mathrm{W}]$} & 6 & \\
Spinning loss & {$[\mathrm{W}]$} & & 17.3 \\
Total loss & {$[\mathrm{W}]$} & 34.3 & 32.6 \\
Efficiency & {$[\%]$} & 94.5 & 94.3 \\
\hline
\end{tabular}

\section{CONCLUSION}

This paper systematically explores the optimization of AFPM machines with different pole counts employing a new two-level surrogate assisted optimization algorithm with expensive 3D models. Optimum designs are achieved by the proper combination of independent variables within wide ranges and by conducting a large scale optimization study. The algorithm greatly improves the computational efficiency by reducing at least to half the number of 3D finite element evaluations. This significantly economizes the computational resources and time, thereby making the optimization of such machines with 3D models feasible.

The paper also identifies the absolute performance limits that can be achieved by fractional horse power AFPM machines with surface magnets within a given envelope. Approximately horizontal and vertical lines obtained on the extremes of the Pareto front indicate that within the geometrical limitations further improvement in efficiency and cost is not probable. The results confirmed that the designs with the best trade-off between the two objectives of loss and mass split the core and copper losses nearly equally.

The combined Pareto front considering machines with pole counts ranging from 10 to 40 obtained in this study illustrates that the highest efficiency is obtained for designs employing 20 poles. An ultra high efficiency axial flux SPM design with 20 poles rated for $0.75 \mathrm{hp}$ is prototyped, demonstrating a measured efficiency of $94.3 \%$.

Furthermore, the effect of the pole count on the optimum design variables is examined to find a relative trend. For instance, it is observed that thinner PMs with a larger pole arc to pole pitch ratio are generally more beneficial for lower pole counts. Within the studied frame size and ratings, a bigger air-gap, a thinner yoke, and a larger slot width result in more efficient, albeit more expensive, designs. Learning such trends can serve as a basis for developing generalized design rules and as a reference for the preliminary stages of the optimum design process, ultimately making the optimization results more accurate as well as computationally affordable.

\section{ACKNOWLEDGMENT}

The support of Regal Beloit Corp., University of Kentucky, the L. Stanley Pigman endowment and the SPARK program, and ANSYS Inc. is gratefully acknowledged.

\section{REFERENCES}

[1] M. Rosu, P. Zhou, D. Lin, D. M. Ionel, M. Popescu, F. Blaabjerg, V. Rallabandi, and D. Staton, Multiphysics Simulation by Design for Electrical Machines, Power Electronics and Drives. Wiley-IEEE Press, 2017.

[2] S. Santoso and H. W. Beaty, Standard Handbook For Electrical Engineers, Seventeenth Edition. McGraw Hill, 2018.

[3] N. Bianchi, S. Bolognani, M. D. Pre, and G. Grezzani, "Design considerations for fractional-slot winding configurations of synchronous machines," IEEE Transactions on Industry Applications, vol. 42, no. 4, pp. 997-1006, July 2006.

[4] N. Taran, V. Rallabandi, D. M. Ionel, and G. Heins, "Coreless and conventional axial flux permanent magnet motors for solar cars," IEEE Transactions on Industry Applications, vol. 54, 2018, Accepted for publication.

[5] J. Cros and P. Viarouge, "Synthesis of high performance PM motors with concentrated windings," IEEE Transactions on Energy Conversion, vol. 17, no. 2, pp. 248-253, Jun 2002.

[6] D. Ishak, Z. Q. Zhu, and D. Howe, "Permanent-magnet brushless machines with unequal tooth widths and similar slot and pole numbers," IEEE Transactions on Industry Applications, vol. 41, no. 2, pp. 584-590, March 2005.

[7] K. F. Konecny, "Compact three-phase permanent magnet rotary machine having low vibration and high performance," U.S. Patent 4774 428A, May 15, 1987.

[8] T. Katsuma and M. Kitoh, "Brushless motor having permanent magnet rotor and salient pole stator," U.S. Patent 4719378A, 23, 1984.

[9] K. Wang, Z. Q. Zhu, and G. Ombach, "Synthesis of high performance fractional-slot permanent-magnet machines with coil-pitch of two slotpitches," IEEE Transactions on Energy Conversion, vol. 29, no. 3, pp. 758-770, Sept 2014.

[10] K. Ahsanullah, R. Dutta, and M. F. Rahman, "Analysis of low-speed IPMMs with distributed and fractional slot concentrated windings for wind energy applications," IEEE Transactions on Magnetics, vol. 53, no. 11, pp. 1-10, Nov 2017.

[11] C. Tang, W. L. Soong, G. S. Liew, and N. Ertugrul, "Effect of pole and slot number changes on the performance of a surface PM machine," in 2012 XXth International Conference on Electrical Machines, Sept 2012, pp. 220-227.

[12] Y. S. Chen, Z. Q. Zhu, and D. Howe, "Vibration of PM brushless machines having a fractional number of slots per pole," IEEE Transactions on Magnetics, vol. 42, no. 10, pp. 3395-3397, Oct 2006.

[13] C. C. Mi, G. R. Slemon, and R. Bonert, "Minimization of iron losses of permanent magnet synchronous machines," IEEE Transactions on Energy Conversion, vol. 20, no. 1, pp. 121-127, March 2005.

[14] S. M. Castano, J. W. Jiang, B. Bilgin, A. Sathyan, H. Dadkhah, and A. Emadi, "An investigation of slot-pole combinations for interior permanent magnet synchronous machines with different magnet topologies," in 2017 IEEE International Electric Machines and Drives Conference (IEMDC), May 2017, pp. 1-8.

[15] Y. Duan and D. M. Ionel, "Nonlinear scaling rules for brushless PM synchronous machines based on optimal design studies for a wide range of power ratings," IEEE Transactions on Industry Applications, vol. 50, no. 2, pp. 1044-1052, March 2014.

[16] N. Taran, D. M. Ionel, and D. G. Dorell, "Two level surrogate assisted differential evolution multiobjective optimization of electric machines using 3D FEA," IEEE Transactions on Magnetics, vol. 54, 2018, Accepted for publication.

[17] A. Fatemi, D. M. Ionel, N. A. O. Demerdash, and T. W. Nehl, "Optimal design of IPM motors with different cooling systems and winding configurations," IEEE Transactions on Industry Applications, vol. 52, no. 4, pp. 3041-3049, July 2016.

[18] C. E. Rasmussen and C. K. I. Williams, Gaussian Processes for Machine Learning. MIT Press, 2006

[19] T. W. Simpson, T. M. Mauery, J. J. Korte, and F. Mistree, "Kriging models for global approximation in simulation-based multidisciplinary design optimization," AIAA Journal, vol. 39, no. 12, pp. 2233-2241, 2001.

[20] G. Heins, D. M. Ionel, D. Patterson, S. Stretz, and M. Thiele, "Combined experimental and numerical method for loss separation in permanentmagnet brushless machines," IEEE Transactions on Industry Applications, vol. 52, no. 2, pp. 1405-1412, March 2016. 